\title{
Investigating the ability of multiparametric MRI to exclude significant prostate cancer prior to transperineal biopsy
}

 \\ Brendan C. Koo, MD; Anne Y. Warren, MD;f Andrew Doble, MD,; Christof Kastner, MD; \\ Ferdia A. Gallagher, $M D^{\dagger \neq}$
}

Dr. Serrao, Dr. Barrett, Dr. Kastner, and Dr. Gallagher contributed equally to the article.

*Department of Radiology, Champalimaud Foundation, Lisbon, Portugal, and Department of Biochemistry, University of Cambridge and Cancer Research, Cambridge, UK; †Department of Radiology, Addenbrooke's Hospital, Cambridge, UK; *University of Cambridge, Cambridge, UK; §Department of Urology, Addenbrooke's Hospital, Cambridge, UK; * Cancer Research Unit, Division of Health Sciences, Warwick Medical School, University of Warwick, Coventry, UK; £Department of Histopathology, Addenbrooke's Hospital

Cite as: Can Urol Assoc J 2015;9(11-12):E853-8 http://dx.doi.org/10.5489/cuaj.2895

Published online December 14, 2015.

\section{Abstract}

Introduction: We characterized false negative prostate magnetic resonance imaging (MRI) reporting by using histology derived from MRI-transrectal ultrasound (TRUS)-guided transperineal (MTTP) fusion biopsies.

Methods: In total, 148 consecutive patients were retrospectively reviewed. Men underwent multiparametric MRI (mpMRI), reported by a consultant/attending radiologist in line with European Society of Urogenital Radiology (ESUR) standards. MTTP biopsy of the lesions was performed according to the Ginsburg recommendations. Cases with an MRI-histology mismatch were identified and underwent a second read by an experienced radiologist. A third review was performed with direct histology comparison to determine a true miss from an MRI-occult cancer. Statistical analysis was performed with McNemar's test.

Results: False negative lesions were identified in $29 \mathrm{MRI}$ examinations $(19.6 \%)$, with a total of 46 lesions. Most false negative lesions (21/46) were located in the anterior sectors of the prostate. The second read led to a significant decrease of false-negative lesions with $7 / 29$ further studies identified as positive on a patientby-patient basis (24.1\% of studies, $p=0.016)$ and $11 / 46$ lesions $(23.9 \% ; p=0.001)$. Of these, 30 lesions following the first read and 23 lesions after the second read were considered significant cancer according to the University College London criteria. However, on direct comparison with histology, most lesions were MRI occult. Conclusion: We demonstrate that MRI can fail to detect clinically relevant lesions. Improved results were achieved with a second read but despite this, a number of lesions remain MRI-occult. Further advances in imaging are required to reduce false negative results.

\section{Introduction}

Current methods for risk stratification of prostate cancer, including serum prostate-specific antigen (PSA) and transrectal ultrasound (TRUS)-guided biopsies, are limited by sampling error and low sensitivity and specificity. ${ }^{1-3}$ TRUSbiopsy can lead to inaccurate grading of $32 \%$ to $42 \%$ of cancers, ${ }^{4-6}$ and may fail to detect $30 \%$ to $50 \%$ of cancers, particularly tumours in the anterior portion of the prostate..$^{7-12}$ The improvement in multiparametric magnetic resonance imaging (mpMRI) in detecting prostate cancer has led to its recommendation in high-risk patients following a negative TRUS biopsy. ${ }^{13}$ MRI can then be used to guide subsequent biopsy either cognitively, in-bore (direct MRI-targeting), or by using MRI-TRUS fusion techniques. ${ }^{14-17}$ The latter combines anatomical MRI localization with the real-time guidance of ultrasound. Repeat biopsy is often undertaken by the transperineal (TP) route as this offers potential advantages over a transrectal route, including better sampling of the anterior and apical regions of the prostate, reduced false negative results, and a sterile approach. ${ }^{18}$

mpMRI has the potential to accurately exclude prostate cancer and reduce biopsy burden. ${ }^{19,20}$ To achieve this, it must have a high negative predictive value (NPV) on a patient-by-patient basis and maintain sufficient accuracy on a lesion-by-lesion basis to correctly stratify patients. ${ }^{21}$ However, current reported figures for the NPV for mpMRI range from $60 \%$ to $100 \% .{ }^{19,22,23}$ This variation depends on the studied population, the MRI protocol, the definitions of significant cancer, and the method of analysis. Another variable is the experience of the radiologist reporting the MRI. ${ }^{24,25}$ The reliability of a negative MRI is a key clinical metric - if the MRI is reported as positive for cancer, the patient will undergo a biopsy irrespective of whether this is a true positive or a false positive; however, a negative MRI 
Serrao et al.

may mean a patient is discharged without need for a biopsy. It is therefore important for an MRI to accurately exclude tumour, and a low false negative (FN) rate is a key determinate of whether this approach is clinically feasible. We therefore aimed to assess and characterize the false-negative mpMRI at our centre, using histology from MRI-TRUS fusion transperineal biopsy sets as a validation tool.

\section{Methods}

This retrospective review of outcomes was granted local ethical approval, with the need for written informed consent waived. Consecutive patients undergoing MRI-TRUS fusion transperineal biopsy from June 2011 to May 2013 were included. Cases where MRI was performed at an outside institution or where the MRI was greater than 8 weeks pre-biopsy, were excluded.

In total, 148 patients were included for analysis, of which 128 patients (86.5\%) had a least 1 prior negative TRUS biopsy. Indications for biopsy included the following: persistently raised PSA, abnormal digital rectal examination, or suspicious histology from previous TRUS-biopsy (high-grade prostatic intraepithelial neoplasia [HG-PIN] or atypical small acinar proliferation).

\section{MRI}

Patients underwent prostate MRI on a 3T HDx or $1.5 \mathrm{~T}$ MR450 scanner (GE-Healthcare, Waukesha, WI) without an endorectal coil. $T_{2}$-weighted Fast Spin-Echo images of the prostate were acquired in the axial, sagittal and coronal planes (TE/TR $=85 / 3700-5000$ ms; field-of-view [FOV] was $24 \times 24 \mathrm{~cm}$; matrix $256 \times 256$; slice thickness/gap 3/1 mm). Diffusion-weighted imaging (DWI) was TE/TR $=60 / 3000$ $3400 \mathrm{~ms}$; matrix $256 \times 256$; slice thickness/gap 4/0 mm; FOV was $24 \times 24 \mathrm{~cm} 1.5 \mathrm{~T}, 28 \times 28 \mathrm{~cm} 3 \mathrm{~T}$; parallel imaging factor 2 ; signal averages were 3 for $1.5 \mathrm{~T}$, 8 for $3 \mathrm{~T}$; b-values were 150, 750, $1400 \mathrm{~s} / \mathrm{mm}^{2}$, with calculated automated apparent diffusion coefficient (ADC) maps.

Exams were reported clinically by a consultant/attending radiologist with at least 3 years prostate MRI reporting experience. The prostate was divided into 27 sectors, with targets defined by location and level of suspicion, as previously described. ${ }^{26} \mathrm{~T}_{2}$-weighted and DWI sequences were evaluated using the Prostate Imaging Reporting and Data System (PI-RADS) structured scoring descriptors, developed by the ESUR. ${ }^{27}$ Based on these descriptors, an overall suspicion for each MR lesion was recorded using a Likert scale: 1 : cancer highly unlikely; 2 : cancer unlikely; 3 : indeterminate for cancer; 4: cancer likely; and 5: cancer highly likely. A positive MRI was defined as a score of $\geq 3$.

\section{Biopsy protocol}

Patients had MTTP biopsies, according to Ginsburg group protocols, performed by 1 of the 3 experienced consultant/attending urologists not blinded to the MRI reports. ${ }^{28}$ Patients had targeted biopsies of MRI detected lesion or lesions (Likert score $\geq 3$ ), followed by 24 to 36 systematic sectoral biopsies. ${ }^{27}$

\section{Histopathology and correlation with MRI}

Biopsies were reported by a consultant/attending uropathologist who was unaware of the MRI findings, and reported according to published guidelines. ${ }^{28}$ Lesion location was described according to the Ginsburg sector map. ${ }^{28}$ Each core was measured and the percentage of cancer estimated. Significant cancer was defined by University College London (UCL) criteria $^{29}$ : green (Gleason $\leq 3+3$, maximum cancer core length $[\mathrm{mCCL}] \leq 3 \mathrm{~mm}$ ), amber (Gleason $3+4$, $\leq 5 \mathrm{~mm}$, or Gleason 3+3, mCCL 4-10 mm) and red (Gleason $\geq 4+3$ or Gleason $3+4, \mathrm{mCCL} \geq 6 \mathrm{~mm}$ or Gleason $3+3, \mathrm{mCCL}$ $\geq 11 \mathrm{~mm}$ ).

\section{Study design}

Histology from all biopsies in 148 patients were reviewed and compared to initial MRI reports. Location of lesions reported by MRI sector map was converted into the Ginsburg sector map nomenclature (Table 1). All cases with one or more MRIhistology mismatches were identified and selected for further characterization, except when mismatch occurred between

\begin{tabular}{|c|c|c|}
\hline $\begin{array}{l}\text { Specimen } \\
\text { name }\end{array}$ & Description & MRI mapping equivalent \\
\hline $1 \mathrm{M}$ & Right anterior medial & 13as/14as/15as (1a/3a) \\
\hline $1 \mathrm{~L}$ & Right anterior lateral & 13as/14as/15as \\
\hline $2 \mathrm{M}$ & Right mid medial (apex) & $1 a / 1 p / 3 a / 3 p / 5 a / 5 p$ \\
\hline $2 \mathrm{~B}$ & Right mid medial base & $1 a / 3 a(1 p)$ \\
\hline $2 \mathrm{~L}$ & Right mid lateral & $2 a / 4 a / 6 a$ \\
\hline $3 \mathrm{M}$ & Right posterior medial & $1 p / 3 p / 5 p$ \\
\hline $3 \mathrm{~L}$ & Right posterior lateral & $2 p / 4 p / 6 p$ \\
\hline $4 \mathrm{M}$ & Left posterior medial & $7 p / 9 p / 11 p$ \\
\hline $4 \mathrm{~L}$ & Left posterior lateral & $8 p / 10 p / 12 p$ \\
\hline $5 \mathrm{M}$ & Left mid medial (apex) & $7 a / 7 p / 9 a / 9 p / 11 a / 11 p$ \\
\hline $5 B$ & Left mid medial base & $7 a / 9 a(7 p)$ \\
\hline $5 \mathrm{~L}$ & Left mid lateral & $8 a / 10 a / 12 a$ \\
\hline $6 \mathrm{M}$ & Left anterior medial & 13as/14as/15as (7a/9a) \\
\hline $6 \mathrm{~L}$ & Left anterior lateral & 13as/14as/15as \\
\hline
\end{tabular}


adjacent prostatic regions. In total, 29 patients were identified with false-negative lesions (i.e., at least 1 lesion on histology not reported on initial MRI). These examinations were then re-read by a radiologist with 5 -years experience in prostate MRI reporting (FAG), blinded to the clinical details and biopsy results. This second read was performed retrospectively, after TP biopsy, and therefore did not affect clinical outcomes. At a subsequent session, the 29 studies were reviewed with histology results available (EMS, FAG), with each false-negative lesion assigned as follows: 1: true miss with lesion retrospectively identified on MRI in biopsy-positive region (false-negative reporting); 2: non-specific MRI features in histology-positive region; 3: no lesion identified (false-negative MRI); 4: miscalled zone (lesion identified, but incorrect zone reported); and 5: image artifact significantly affecting interpretation.

\section{Statistics}

Data analysis was performed with SPSS (v21, IBM-SPSS, Chicago, IL). Statistical significance was determined using McNemar's test to assess the null hypothesis of marginal homogeneity, which states that the probability of each characterization by the 2 raters is the same. Since the numbers in discordant cells were small, exact binominal probability $p$ values were used. A $p$ value $<0.05$ was considered statistically significant. The effect of sector location on cancer significance was estimated as an odds ratios (OR) using logistic regression.

\section{Results}

Of the 148 patients, 73 had a least 1 biopsy core which was positive for cancer (49.3\%) (Table 2). A total of 232

\begin{tabular}{|c|c|c|}
\hline & $\begin{array}{l}\text { Total values } \\
\text { (148 patients) }\end{array}$ & $\begin{array}{l}\text { MRI FN values ( } 29 \\
\text { patients) }\end{array}$ \\
\hline Age, years; median (range) & $65(48-79)$ & $67(52-77)$ \\
\hline $\begin{array}{l}\text { Initial PSA, ng/mL; median } \\
\text { (range) }\end{array}$ & $9.55(0.7-150)$ & $11.66(1.3-36.5)$ \\
\hline \multicolumn{3}{|l|}{ Biopsy } \\
\hline $\begin{array}{l}\text { No. cores per patient; mean } \\
\text { (range) }\end{array}$ & $30(19-56)$ & $28(19-39)$ \\
\hline Total no. cores (mean) & $4393(29.7)$ & $818(28.2)$ \\
\hline Gleason grade (\%) & $\begin{array}{c}\mathrm{n}=73 \text { biopsy } \\
\text { positive (in } 148 \\
\text { patients) }\end{array}$ & $\begin{array}{c}\mathrm{n}=46 \text { lesions (in } \\
29 \text { patients) }\end{array}$ \\
\hline $3+3$ & $38(52.1 \%)$ & $23(50 \%)$ \\
\hline $3+4$ & $16(21.9 \%)$ & $9(19.6 \%)$ \\
\hline $4+3$ & $4(5.5 \%)$ & $6(13 \%)$ \\
\hline$\geq 4+4$ & $15(20.5 \%)$ & $8(17.4 \%)$ \\
\hline
\end{tabular}

lesions from the 148 patients were prospectively reported as "MRI positive" (mean 1.57 lesions/patient; median 2), and proceeded to a targeted biopsy, of which 174 (75\%) were positive for cancer. A total of 220 positive biopsies were identified histologically, with $102 / 220$ as UCL category green and 118/200 as amber or red. Of the 220 positive biopsies, 46 (20.9\%) were in areas determined falsely negative on MRI.

Of the 148 pateints, 29 (19.6\%) had at least $1 \mathrm{FN}$ lesion on MRI, with 28/29 patients having $\geq 1$ lesion reported elsewhere in the gland and histologically confirmed as cancer; for one, no lesion was described. For these 29 patients, 23 $(79.3 \%)$ were scanned a $3 \mathrm{~T}$ and $6(20.7 \%)$ at $1.5 \mathrm{~T}$. The probability of classifying prostatic sectors into positive (lesion present) or negative (no lesion) by the 2 readers was significantly different $(p=0.001)$. The second MRI read led to a significant decrease of false negative lesions on a patient-by-patient basis (reduced $24.1 \%$; in $7 / 29$ patients; $p=0.016)$ and a lesion-by-lesion basis $(23.9 \%, 11 / 46$ lesions, $p=0.001$ ) (Table 3 ). The second read improved sensitivity for lesion detection from $79 \%$ to $84 \%$. Of the 46 lesions, 30 were in 18 of the 29 patients missed at first read; they represented $U C L$-defined significant cancer and the number of lesions reduced to 23 lesions $(p=0.016)$ in 12 patients $(p=0.031)$ at second read (Table 3$)$.

At the second read, of the $35 \mathrm{FN}$ lesions, 15 were MRIinvisible even when comparing directly to histology. Nonspecific focal features were found in 10/35 lesions after the second read, with $7 / 10$ being significant cancers. True misses (Fig. 1) still accounted for 7/35 lesions after the second reading.

Table 3. Retrospective MRI classification of the total false negative MRI lesions and of those that represented significant cancer at biopsy

\begin{tabular}{lcc}
\hline MRI Classification & $\begin{array}{c}\text { Initial } \\
\text { report }\end{array}$ & Second read \\
\hline True miss (FN report) & 10 & 7 \\
Non-specific features & 12 & 10 \\
No feature of a focal lesion (FN MRI) & 19 & 15 \\
Miscalled zone & 3 & 1 \\
Difficult interpretation & 2 & 2 \\
Total (lesions): & 46 & $35^{*}$ \\
\hline MRI classification & Significant cancers (amber \\
& or red on UCL criteria) \\
\hline True miss & MRI report & Second read \\
Non-specific features & 7 & 4 \\
No features of a focal lesion & 8 & 7 \\
Miscalled zone & 11 & 10 \\
Difficult interpretation & 2 & 0 \\
Total (lesions) & 2 & 2 \\
\hline${ }^{*} p \leq 0.05$. FN: false negative; MRI: magnetic resonance imaging. &
\end{tabular}



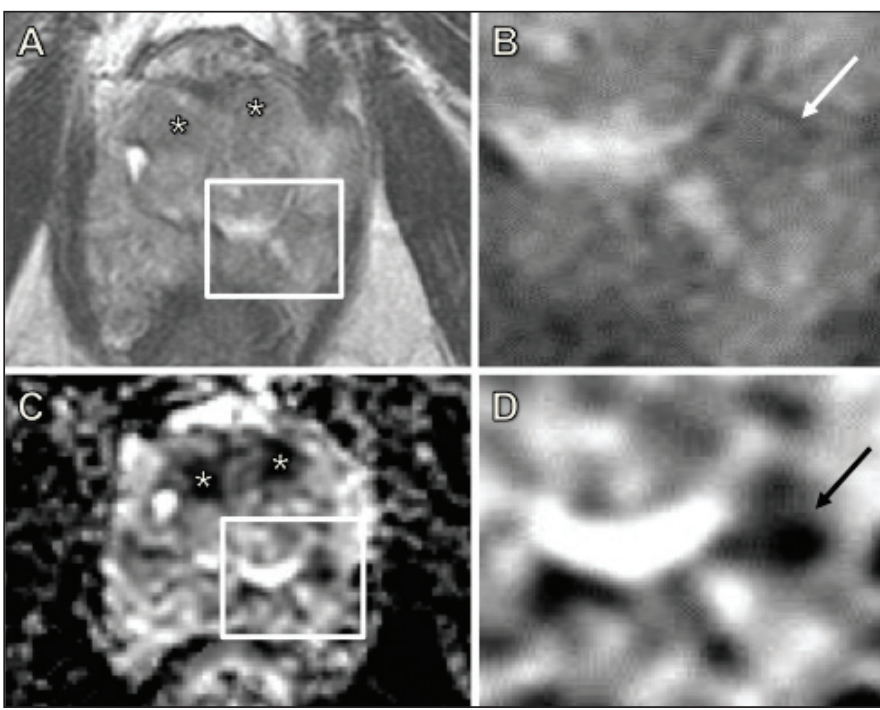

Fig. 1. Demonstration of a true miss. A 69-year-old man with a prostate-specific antigen of $18 \mathrm{ng} / \mathrm{mL}$. Bilateral anterior high probability targets $\left({ }^{*}\right)$ were called on axial T2 images (A) and apparent diffusion coefficient (ADC) maps (C). Histology confirmed a Gleason $4+3$ lesion in $25 \%$ of cores from the anterior zones ( 1 and 6). A magnified axial T2 image (B) and ADC map (D) is shown corresponding to each inset box. There was an additional Gleason 3+4 lesion in the left posterior lateral zone (4L) involving $5 \%$ of the core. The latter was missed even after two separate reads, but on direct comparison with the histology, the lesion was identified (arrows in B and D).

The greatest proportion of false negative lesions (21/46) were in the anterior prostate sectors (Fig. 2). Although a higher proportion of significant cancers were also located anteriorly (12/30), and the sector location had no effect on cancer significance (OR 1.056, $p=0.544$ ).

Of the 29 patients with $\mathrm{FN}$ lesions, 3 underwent prostatectomy, 10 radiotherapy with hormonal therapy, 2 brachytherapy, 2 hormonal therapy, 2 focal-therapy, and 10 enrolled to active surveillance. Analysis of the prostatectomy patients showed good agreement between biopsy and final pathology (Fig. 3), except in 1 patient with over-grading by TP biopsy (Gleason 4+5; final pathology $4+3$ with tertiary 5).

\section{Discussion}

$\mathrm{mpMRI}$ of the prostate is becoming established in the routine workup of patients with suspected prostate cancer and is increasingly used for lesion detection in men with negative TRUS biopsies and with persistent suspicion of cancer. ${ }^{13,30}$ MRI-guidance in this setting increases the detection of clinically significant cancer compared to standard approaches. ${ }^{15,31,32} \mathrm{MRI}$ may in the future be performed prior to biopsy as a strategy to triage men with raised PSA and to select the best approach for biopsy. ${ }^{3,20}$ This study has shown that initial mpMRI missed at least 1 focus of cancer in 29/148 (19.6\%) of patients, corresponding to 46 lesions, $65 \%$ of which were considered significant cancers.

Previous studies have demonstrated that approximately

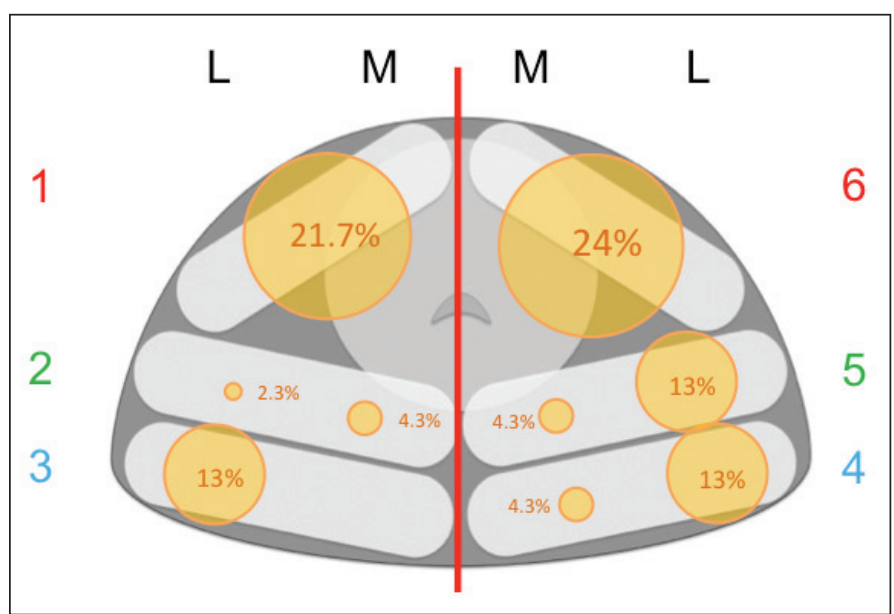

Fig. 2. Distribution of the false negative lesions. The relative size of circles reflects the percentage of false negatives in each prostate sector in the axial plane, according to the Ginsburg mapping system. This system divides the prostate into 3 antero-posterior with no differentiation between apex, mid and base (except for 2B and 5B which are not shown), unlike the PI-RADS system, which is frequently used for prostate magnetic resonance imaging reporting.

one-fifth of men with histologically-proven cancer on standard biopsy had a negative MRI. ${ }^{15,16,33}$ It is noteworthy that these studies were performed in biopsy-naïve men, whereas our cohort included men with a previous negative TRUS biopsy. We are therefore likely to have excluded larger, more posteriorly located tumours, for which MRI is known to have a higher sensitivity. The second reading, despite its retrospective nature, was shown to be beneficial in reducing both the number of true misses and the overall number of FN examinations. This highlights the potential advantage for double-reading of selected high-risk cases by an experienced radiologist, or possibly even routine double-reading, which is standard practice in some areas of radiology, such as screening mammography.

Most FN MRI lesions were not identified on MRI even after retrospective review. One such case had no MRI-detectable lesions despite the presence of significant cancer in 3 different regions. This may reflect the volume of diseased tissue required per MRI voxel for lesions to be detected, sparsity of tumour growth, or the intrinsic limitations of MRI. ${ }^{34-36}$ Indeed, MRI is known to be poor at detecting low-grade, low-volume cancer, lacking sensitivity even in cases where the predominant Gleason pattern is 4 , but the cancer volume is $<0.2 \mathrm{~cm}^{3} .{ }^{36-38}$ These factors reflect the need for further advances in imaging to detect such lesions. We found that anterior lesions were more likely to be missed than lesions elsewhere within the prostate, which reflects the known difficulty in identifying cancer within the heterogeneous transition zone (TZ) and fibromuscular stroma. ${ }^{39,40}$

Our study has limitations, including its retrospective nature. Despite the fact that transperineal template biopsies perform well in detecting significant disease, any biopsy technique is prone to sampling error. ${ }^{29,41}$ As this study was 

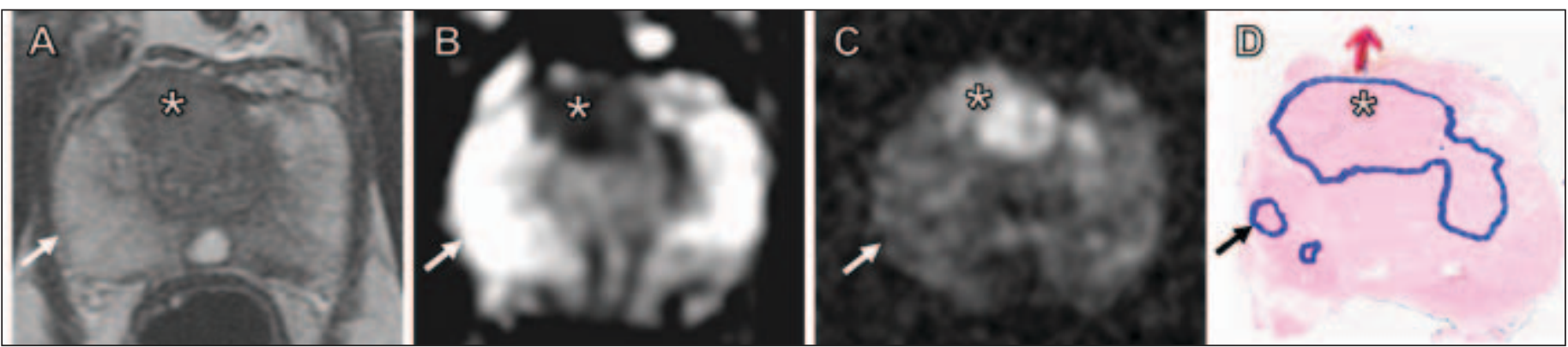

Fig. 3. Demonstration of a false negative magnetic resonance imaging (MRI) where no target could be identified to correspond to the histological lesion. MRI and histology slides from a 70 year-old man presenting with a prostate-specific antigen of $6.4 \mathrm{ng} / \mathrm{mL}$, who underwent a subsequent prostatectomy. Initial MRI reported a 2-cm, high probability solitary lesion $(*)$ in the anterior gland on T2-weighted imaging (A), with restricted diffusion on apparent diffusion coefficient maps (B) and $b=1400$ diffusion-weighted imaging (C). This was confirmed as Gleason $4+5$ at MRI-transrectal ultrasound fusion transperineal (MTTP) biopsy (involving all 4 target cores) and on subsequent histology slides (D); red arrow in D indicates extra-capsular extension. MTTP biopsy also showed cancer in the right posterior lateral segment, and prostatectomy specimen confirmed a small $3 \mathrm{~mm}$ focus of Gleason 3+3 disease (black arrow in D). The lesion was not visible on any MRI sequence (white arrows), confirming this to be a false negative, MR-occult lesion.

performed as part of routine clinical practice, MRI was undertaken at both $1.5 \mathrm{~T}$ and $3 \mathrm{~T}$. The study was not designed to assess whether field strength affects the false negative rate of $\mathrm{MRI}$ and further research is required to determine whether $3 \mathrm{~T}$ imaging of the prostate yields a lower false negative rate than 1.5T. Additionally, dynamic contrast-enhanced (DCE) MRI was not performed as it was not standard-of-care in our institution at the time of this study, although there is some evidence that it can help improve sensitivity over DWI alone. $^{27,42,43}$ However, most lesions were in the TZ and the recently updated PI-RADS guidelines suggest DCE-MRI has no role to play in assessment of the TZ in the presence of adequate DWI and T2-weighted imaging. ${ }^{44}$ There is differing nomenclature between the radiological sector-maps for reporting MRI-tumour location and the Ginsburg uropathology system used for obtaining and reporting biopsies; this may account for some analysis errors, as correlation of the MRI location to biopsy sectors becomes more challenging. The radiology map employed here incorporated 2 regions in the anterio-posterior plane, compared to 3 in the Ginsburg system (Fig.2); interestingly, a more updated radiological map now includes 3 anterio-posterior sectors medially. ${ }^{45}$ Conversely, the Ginsburg system does not differentiate the apex, mid and base of the prostate; although this can be overcome by the inking of biopsy cores, this will incur additional time and cost. ${ }^{26,28}$

It is important to note that in clinical practice factors other than MRI are used to help determine whether a patient requires further investigation. This study has been designed to assess the $\mathrm{FN}$ rate for MRI alone; combining imaging with other investigations to reduce FNs are required in the future. We have demonstrated that a high proportion of FN lesions can be reduced by a second read, which is important information for the clinical community and underlines the need for further studies to address how multiple tests can be used together to reduce the need for biopsy.

\section{Conclusion}

This study shows that MRI reporting can miss clinically relevant lesions. Improved results were achieved with a second read by an experienced radiologist. However, despite careful correlation to histology results, a number of lesions remained occult on MRI, demonstrating the limitations of existing sequences for the detection of some lesions and the need for further improvements in imaging in the future.

Acknowledgements: The authors acknowledge research support from National Insitute of Health Research Cambridge Biomedical Research Centre, Cancer Research UK, Cancer Research UK and the Engineering and Physical Sciences Research Council Imaging Centre in Cambridge and Manchester and the Cambridge Experimental Cancer Medicine Centre.

Competing interests: The authors all declare no competing financial or personal interests; with the exception of Dr. Gallagher, who has received research grants from GE Healthcare and GSK in the past 2 years.

This paper has been peer-reviewed.

\section{References}

1. Schroder FH, Hugosson J, Roobol MJ, et al. Screening and prostate-cancer mortality in a randomized European study. N Engl J Med 2009;360:1320-8. http://dx.doi.org/10.1056/NEJMoa0810084

2. Hugosson J, Carlsson $S$, Aus $G$, et al. Mortality results from the Goteborg randomised population-based prostate-cancer screening trial. Lancet Oncol 2010;11:725-32. http://dx.doi.org/10.1016/S14702045(10)70146-7

3. Kirkham AP, Haslam P, Keanie JY, et al. Prostate MRI: Who, when, and how? Report from a UK consensus meeting. Clin Radiol 2013;68:1016-23. http://dx.doi.org/10.1016/i.crad.2013.03.030

4. Isariyawongse BK, Sun L, Banez LL, et al. Significant discrepancies between diagnostic and pathologic Gleason sums in prostate cancer: The predictive role of age and prostate-specific antigen. Urology 2008;72:882-6. http://dx.doi.org/10.1016/i.urology.2008.02.021

5. Lattouf JB, Saad F. Gleason score on biopsy: Is it reliable for predicting the final grade on pathology? BJU Int 2002;90:694-8; discussion 698-9. http://dx.doi.org/10.1046/j.1464-410X.2002.02990.x 
Serrao et al.

6. King CR. Patterns of prostate cancer biopsy grading: Trends and clinical implications. Int I Cancer 2000;90:305-11. http://dx.doi.org/10.1002/1097-0215(20001220)90:6<305::AID$\mathrm{IJCl}>3.0 . \mathrm{CO} ; 2-\mathrm{U}$

7. Levine $M A$, Ittman $M$, Melamed J, et al. Two consecutive sets of transrectal ultrasound guided sextant biopsies of the prostate for the detection of prostate cancer. J Urol 1998;159:471-5. http://dx.doi. org/10.1016/50022-5347(01)63951-X

8. Lecornet E, Ahmed HU, Hu Y, et al. The accuracy of different biopsy strategies for the detection of clinically important prostate cancer: A computer simulation. J Urol 2012;188:974-80. http://dx.doi. org/10.1016/i.juro.2012.04.104

9. Borboroglu PG, Comer SW, Riffenburgh RH, et al. Extensive repeat transrectal ultrasound guided prostate biopsy in patients with previous benign sextant biopsies. J Urol 2000;163:158-62. http://dx.doi. org/10.1016/50022-5347(05)67994-3

10. Haas GP, Delongchamps NB, Jones RF, et al. Needle biopsies on autopsy prostates: Sensitivity of cancer detection based on true prevalence. J Natl Cancer Inst 2007;99:1484-9. http://dx.doi.org/10.1093/ jnci/diml53

11. Delongchamps NB, de la Roza G, Jones R, et al. Saturation biopsies on autopsied prostates for detecting and characterizing prostate cancer. BJU Int 2009;103:49-54. http://dx.doi.org/10.1111/i.1464410X.2008.07900.x

12. Wright IL, Ellis WJ. Improved prostate cancer detection with anterior apical prostate biopsies. Urol Oncol 2006;24:492-5. http://dx.doi.org/10.1016/j.urolonc.2006.03.003

13. Graham J, Kirkbride P, Cann K, et al. Prostate cancer: summary of updated NICE guidance. BMJ 2014;348:f7524. http://dx.doi.org/10.1136/bmi.f7524

14. Hadaschik BA, Kuru TH, Tulea C, et al. A novel stereotactic prostate biopsy system integrating preinterventional magnetic resonance imaging and live ultrasound fusion. J Urol 201 1;186:2214-20. http:// dx.doi.org/10.1016/i.juro.2011.07.102

15. Moore CM, Robertson NL, Arsanious N, et al. Image-guided prostate biopsy using magnetic resonance imaging-derived targets: A systematic review. Eur Urol 2013;63:125-40. http://dx.doi.org/10.1016/i. eururo.2012.06.004

16. Haffner J, Lemaitre L, Puech P, et al. Role of magnetic resonance imaging before initial biopsy: Comparison of magnetic resonance imaging-targeted and systematic biopsy for significant prostate cancer detection. BJU Int 2011;108:E171-8. http://dx.doi.org/10.1111/i.1464-410X.2011.10112.x

17. Robertson NL, Emberton M, Moore CM. MRl-targeted prostate biopsy: A review of technique and results. Nat Rev Urol 2013;10:589-97. http://dx.doi.org/10.1038/nrurol.2013.196

18. Chang DT, Challacombe B, Lawrentschuk N. Transperineal biopsy of the prostate-is this the future? Nat Rev Urol 2013;10:690-702. http://dx.doi.org/10.1038/nrurol.2013.195

19. Abd-Alazeez M, Kirkham A, Ahmed HU, et al. Performance of multiparametric MRI in men at risk of prostate cancer before the first biopsy: A paired validating cohort study using template prostate mapping biopsies as the reference standard. Prostate Cancer Prostatic Dis 2014;17:40-6. http://dx.doi. org/10.1038/pcan.2013.43

20. Ahmed HU, Kirkham A, Arya M, et al. Is it time to consider a role for MRI before prostate biopsy? Nat Rev Clin Oncol 2009;6:197-206. http://dx.doi.org/10.1038/nrclinonc.2009.18

21. Wilt TJ, Brawer MK, Jones KM, et al. Radical prostatectomy versus observation for localized prostate cancer. N Engl J Med 2012;367:203-13. http://dx.doi.org/10.1056/NEJMoal113162

22. Villeirs GM, De Meerleer G0, De Visschere PJ, et al. Combined magnetic resonance imaging and spectroscopy in the assessment of high grade prostate carcinoma in patients with elevated PSA: A singleinstitution experience of 356 patients. Eur J Radiol 2011;77:340-5. http://dx.doi.org/10.1016/i. eirad.2009.08.007

23. Kuru TH, Roethke MC, Seidenader J, et al. Critical evaluation of magnetic resonance imaging targeted, transrectal ultrasound guided transperineal fusion biopsy for detection of prostate cancer. I Urol 2013;190:1380-6. http://dx.doi.org/10.1016/i.juro.2013.04.043

24. Akin 0 , Riedl CC, Ishill NM, et al. Interactive dedicated training curriculum improves accuracy in the interpretation of MR imaging of prostate cancer. Eur Radiol 2010;20:995-1002. http://dx.doi.org/10.1007/ s00330-009-1625-x

25. Gaziev G, Wadhwa K, Barrett T, et al. Defining the learning curve for multiparametric magnetic resonance imaging (MRI) of the prostate using MRl-transrectal ultrasonography (TRUS) fusion-guided transperineal prostate biopsies as a validation tool. BJU Int 2014; http://dx.doi.org/10.1111/bju.12892

26. Dickinson L, Ahmed HU, Allen C, et al. Magnetic resonance imaging for the detection, localisation, and characterisation of prostate cancer: Recommendations from a European consensus meeting. Eur Urol 2011;59:477-94. http://dx.doi.org/10.1016/.eururo.2010.12.009
27. Barentsz J0, Richenberg J, Clements R, et al. ESUR prostate MR guidelines 2012. Eur Radiol 2012;22:74657. http://dx.doi.org/10.1007/s00330-011-2377-y

28. Kuru TH, Wadhwa K, Chang RT, et al. Definitions of terms, processes and a minimum dataset for transperineal prostate biopsies: A standardization approach of the Ginsburg Study Group for Enhanced Prostate Diagnostics. BJU Int 2013;112:568-77. http://dx.doi.org/10.1111/bju.12132

29. Ahmed HU, Hu Y, Carter T, et al. Characterizing clinically significant prostate cancer using template prostate mapping biopsy. J Urol 2011;186:458-64. http://dx.doi.org/10.1016/i.juro.2011.03.147

30. Nelson AW, Harvey RC, Parker RA, et al. Repeat prostate biopsy strategies after initial negative biopsy: Meta-regression comparing cancer detection of transperineal, transrectal saturation and MRI guided biopsy. PLoS One 2013;8:e57480. http://dx.doi.org/10.1371/journal.pone.0057480

31. Kuru TH, Saeb-Parsy K, Cantiani A, et al. Evolution of repeat prostate biopsy strategies incorporating transperineal and MRI-TRUS fusion techniques. World J Urol 2014;32:945-50. http://dx.doi. org/10.1007/s00345-014-1334-1

32. Lawrence EM, Tang SY, Barrett T, et al. Prostate cancer: Performance characteristics of combined T2W and DW-MRI scoring in the setting of template transperineal re-biopsy using MR-TRUS fusion. Eur Radiol 2014;24:1497-505. http://dx.doi.org/10.1007/s00330-014-3159-0

33. Park BK, Park JW, Park SY, et al. Prospective evaluation of 3-T MRI performed before initial transrectal ultrasound-guided prostate biopsy in patients with high prostate-specific antigen and no previous biopsy. AJR Am J Roentgenol 2011;197:W876-81. http://dx.doi.org/10.2214/AJR.11.6829

34. Puech P, Potiron E, Lemaitre L, et al. Dynamic contrast-enhanced-magnetic resonance imaging evaluation of intraprostatic prostate cancer: Correlation with radical prostatectomy specimens. Urology 2009;74:1094-9. http://dx.doi.org/10.1016/j.urology.2009.04.102

35. Vargas HA, Akin O, Franiel T, et al. Diffusion-weighted endorectal MR imaging at $3 \mathrm{~T}$ for prostate cancer: Tumour detection and assessment of aggressiveness. Radiology 2011;259:775-84. http://dx.doi. org/10.1148/radiol.11102066

36. Langer DL, van der Kwast TH, Evans AJ, et al. Intermixed normal tissue within prostate cancer: Effect on MR imaging measurements of apparent diffusion coefficient and T2-sparse versus dense cancers. Radiology 2008;249:900-8. http://dx.doi.org/10.1148/radiol.2493080236

37. Kim JY, Kim SH, Kim YH, et al. Low-risk prostate cancer: The accuracy of multiparametric MR imaging for detection. Radiology 2014;271:435-44. http://dx.doi.org/10.1148/radiol.13130801

38. Lemaitre L, Puech P, Poncelet E, et al. Dynamic contrast-enhanced MRI of anterior prostate cancer: Morphometric assessment and correlation with radical prostatectomy findings. Eur Radiol 2009;19:47080. http://dx.doi.org/10.1007/s00330-008-1153-0

39. Ouzzane A, Puech $P$, Lemaitre $L$, et al. Combined multiparametric MRI and targeted biopsies improve anterior prostate cancer detection, staging, and grading. Urology 2011;78:1356-62. http://dx.doi. org/10.1016/i.urology.2011.06.022

40. Akin 0, Sala E, Moskowitz CS, et al. Transition zone prostate cancers: Features, detection, localization, and staging at endorectal MR imaging. Radiology 2006;239:784-92. http://dx.doi.org/10.1148/ radiol.2392050949

41. Bittner N, Merrick GS, Butler WM, et al. Incidence and pathological features of prostate cancer detected on transperineal template guided mapping biopsy after negative transrectal ultrasound guided biopsy. $J$ Urol 2013;190:509-14. http://dx.doi.org/10.1016/i.juro.2013.02.021

42. Isebaert S, Van den Bergh L, Haustermans K, et al. Multiparametric MRI for prostate cancer localization in correlation to whole-mount histopathology. J Magn Reson Imaging 2013;37:1392-401. http:// dx.doi.org/10.1002/imri.23938

43. Tanimoto A, Nakashima J, Kohno H, et al. Prostate cancer screening: The clinical value of diffusion-weighted imaging and dynamic MR imaging in combination with T2-weighted imaging. J Magn Reson Imaging 2007;25:146-52. http://dx.doi.org/10.1002/imri.20793

44. Barrett T, Turkbey B, Choyke PL. PI-RADS version 2: What you need to know. Clin Radiol 2015;70:116576. http://dx.doi.org/10.1016/i.crad.2015.06.093

45. Barentsz J, Villers A, Schouten M. ESUR prostate MR guidelines. Eur Radiol 2013;23:2322-3. http:// dx.doi.org/10.1007/s00330-013-2896-9

Correspondence: Dr. Tristan Barrett, Addenbrooke's Hospital, Hills Road, Cambridge, CB2 OQQ United Kingdom; tristan.barrett@gmail.com 